\title{
Knowledge and reported practices of men and women on maternal and child health in rural Guinea Bissau: a cross sectional survey
}

\author{
Rebecca King*1,3, Vera Mann² and Peter D Boone ${ }^{1}$
}

\begin{abstract}
Background: Participatory health education interventions and/or community-based primary health care in remote regions can improve child survival. The most recent data from Guinea Bissau shows that the country ranks $5^{\text {th }}$ from bottom globally with an under-five mortality rate of 198 per 1000 live births in 2007. EPICS (Enabling Parents to Increase Child Survival) is a cluster randomised trial, which is currently running in rural areas of southern Guinea Bissau. It aims to evaluate whether an intervention package can generate a rapid and cost-effective reduction in under-five child mortality. The purpose of the study described here was to understand levels of knowledge on child health and treatment-seeking and preventative behaviours in southern Guinea Bissau in order to develop an effective health education component for the EPICS trial. The study also aimed to assess the effect of gender and ethnicity on knowledge and behaviour.
\end{abstract}

Methods: Women and men were interviewed in their households using a structured questionnaire. Characteristics of the households and of the interviewed women and men were tabulated. The number of correct answers given to the health knowledge and practice questions and their percentage distribution were tabulated by items and by gender. An overall health knowledge score was derived.

Results: There are low levels of appropriate knowledge on child health, some inappropriate practices and generally low vaccination coverage. Health knowledge scores improve significantly amongst those who have accessed higher education. Differences in health knowledge between women and men become insignificant once age and education are accounted for.

Conclusions: Health education activities should be an integral part of a package to improve child survival in rural Guinea Bissau. These activities should focus on diarrhoea, malaria, pneumonia, pregnancy, delivery, neonatal care and vaccination coverage, as these are areas where knowledge and practices were found to be inadequate in this study. Men as well as women should be involved in these activities. Prior to developing health education interventions in similar settings, studies to assess areas to be targeted should be conducted.

\section{Background}

Child survival came to the forefront of the global health agenda with the 2003 series in The Lancet [1-5]. The opening report stated that an estimated 10.8 million children aged under-five were dying globally in 2000. Approximately $90 \%$ of these deaths were occurring in 42 countries. The major causes of mortality were identified as diarrhoea and pneumonia, whilst neonatal disorders,

* Correspondence: r.king@leeds.ac.uk

1 Effective Intervention, Centre for Economic Performance, London School of Economics, London, UK

Full list of author information is available at the end of the article malaria and HIV contributed substantially in certain regions [1]. An estimated $63 \%$ of these under-five deaths could be prevented if current knowledge on available and feasible interventions is translated into effective action [2]. One of the targets of the United Nations' Millennium Development Goals (MDGs) is to reduce the under-five mortality rate by two-thirds between 1990 and 2015 (MDG4). UNICEF, WHO and other experts agreed on a minimum set of key indicators for monitoring progress to achieve MDG4. These include oral rehydration therapy (ORT) and continued feeding for diarrhoea, the use of 
insecticide treated mosquito nets (ITNs) and antimalarial treatment for under-fives, antibiotic treatment for pneumonia, immunization coverage (tetanus, measles and DTP3), and timely initiation of breastfeeding and exclusive breast feeding until 6 months [6].

There is evidence to suggest that participatory health education interventions and/or community-based primary health care in remote regions can improve child survival $[7,8]$. These community-based interventions target health knowledge and promote appropriate treatment-seeking and preventative behaviours. In Nepal, an intervention using women's health groups led to a reduction in neonatal mortality of nearly $30 \%$.These groups met monthly to identify problems and implement and evaluate strategies to tackle the identified problems [9]. A similar approach saw a significant decrease in perinatal mortality in Bolivia [10,11]. In India, home-based neonatal care and management of sepsis by trained community health workers led to a $62 \%$ decline in neonatal mortality when compared to a control region that surrounded the project area. Moreover, fatality from sepsis declined from $16.6 \%$ to $2.8 \%$ [12]. The evidence suggests that an intensive community health education programme in combination with mentoring of community health workers and improved availability of services and materials at the community level may lead to major, cost-effective declines in child mortality.

The most recent data ranks Guinea Bissau $5^{\text {th }}$ from the bottom globally. The neonatal mortality rate was 47 per 1000 live births in 2004 and the country had an underfive mortality rate of 198 per 1000 live births and an infant mortality rate of 118 per 1000 live births in 2007 [13]. There is very little information on the causes of child deaths in Guinea Bissau, as the country was not included in the epidemiological profiles supplied in the Child Survival series. However, nearby countries were included in Profile 2 and diarrhoea, malaria, pneumonia and neonatal disorders were identified as the leading causes of child mortality [1].

EPICS (Enabling Parents to Increase Child Survival) is a cluster randomised trial, which is currently running in rural areas of southern Guinea Bissau [14]. It aims to evaluate whether an intervention package can generate a rapid and cost-effective reduction in under-five child mortality. The package includes health education through health clubs and house-to-house visits. It also includes intensive training and supervision of village health workers and community-based birth attendants, improved outreach services and enhanced institutional delivery services. A maternal birth history survey conducted in the region before the trial started in 2007 found an under-five child mortality rate of 154 per 1000 live births, as reported by women aged 12 to 49 for their 2002 to 2007 pregnancy history. This is somewhat lower than nationally reported [13].

The aims of this study were to understand levels of knowledge on child health as well as the treatment-seeking and preventative behaviours of the inhabitants of the trial area. The study was conducted prior to the start of the trial in order to develop an appropriate and effective health education component. The study also aimed to assess the effect of gender and ethnicity on knowledge and behaviour.

This article reports on the knowledge and reported practices of men and women on maternal and child health in two districts of southern Guinea Bissau. It also reports the effect of gender and ethnicity of knowledge and behaviour.

\section{Methods}

\section{Study setting and participants}

The study was conducted in the two rural districts of southern Guinea Bissau (Quinara and Tombali) in which the EPICS trial is being implemented. Villages in the region were considered eligible for the trial if they were believed to have a population of approximately 300 inhabitants. The villages were mapped and enumerated during the maternal birth history baseline survey. Clusters were formed from one or more villages in order to create an average population of 350 per cluster. This process resulted in 241 villages being organised into 146 clusters for inclusion in the trial [14]. This baseline study of health knowledge and practice was conducted in 31 of these villages after the clusters had been identified but before they were randomised into control and intervention arms. The villages were selected on the basis of their accessibility (in the rainy season, when this study was conducted, some of the villages are inaccessible). The selected villages included those that had majority Fula (13), Beafada (10) and Nalu (5) populations. These are ethnic groups that normally identify themselves as Muslim. Two villages had Susu populations and one had Balanta population as majority.

In each selected village, 10 households out of those that had already been mapped were randomly selected for this study. Within each household, one woman who was a primary carer of a child aged five or under and one man who lived in the same household as the woman (most commonly her husband) were selected for interview. If a visited household had more than one eligible woman and/or man, the ones who were interviewed were randomly selected.

\section{Data collection and instruments}

A fully structured questionnaire (Additional file 1) was developed and interviews were carried out by trained field workers who were supervised. The questionnaire -- 
which was in part based on questions from DHS surveys collected information on knowledge and reported practices on the key indicators affecting child survival [3]. It was arranged into seven sections on household characteristics, respondent characteristics, health knowledge, pregnancy and delivery, vaccination status, treatmentseeking behaviour and household observation. Section one was completed with the woman and man together. Sections two, three and parts of six were completed with both the woman and man, interviewed separately. Sections four, five, parts of six and seven were completed only with the woman. Sections one and two had questions with only one possible answer. The other sections had two types of question: those for which only one answer could be given and those for which more than one answer was possible.

The questionnaire was piloted in two different villages in southern Guinea Bissau and revisions were made before the survey was conducted. These villages were excluded from the survey. A team of six field workers -recruited from Bissau - and one field supervisor were provided with intensive classroom and field-based training as well as a detailed manual of survey guidelines. Field workers conducted the survey in Kriol or, where necessary, directly or through translation in appropriate local languages.

\section{Data analysis}

Characteristics of the households and of the interviewed women and men were tabulated. These included background characteristics of the households and demographic characteristics of the respondents by gender. Descriptive statistics for continuous variables included the mean, standard deviation, median, and range and for categorical variables the numbers and percentages. The number of correct answers given to the health knowledge and practice questions and their percentage distribution were tabulated by items and by gender (as appropriate).

An overall health knowledge score was derived by summing the total number of correct responses given to the fifteen health knowledge questions in section three of the questionnaire. Questions with more than one possible correct answer were weighted by the inverse of the total number of correct answers so that no single question contributed more than one point out of fifteen to the score. Factors affecting health knowledge scores were investigated using simple linear regression models. Gender was used as a single binary predictor. Education was categorised into primary (grade 1-6), secondary (grade 79), higher (grade 10-12) or Koranic education. Ethnicity was included in the models as Balanta, Beafada, Fula, Nalu, Mandinka, Susu and Bijagos, or other. Age and an indicator of household crowdedness (the number of people per room within the house) were used as continuous variables. Robust standard errors were used to allow for clustering within villages. The final multiple linear regression includes gender and ethnicity and other factors which either had a statistically significant effect on obtained health knowledge score themselves or confounded the effect of gender and/or ethnicity.

\section{Ethical considerations}

This study was approved by the ethics committees of 'The Centre for Coordination of the Research of the Ministry Of Health' in Guinea Bissau (NCP-021/2007) and the London School of Hygiene and Tropical Medicine (5173).

\section{Results}

\section{Descriptive statistics}

The general characteristics of the 310 households are presented in Table 1 . An average of 11 people and 3 children aged under-five lived in each household. An average of 2.5 people shared a room. This table also includes fieldworkers' observations on household facilities. In 295 households (95\%) a bed net was observed in the place where it was said the youngest child sleeps (data not in table). $82 \%$ of households had a hand washing facility close to where the food is prepared, but only $17 \%$ had soap to wash the hands with. $81 \%$ of the households had a latrine.

Table 2 presents the demographic characteristics of women and men interviewed for this study as well as their education and literacy level. In 216 households the interviewed man was the husband of the woman (data not shown in the table). On average, women were much younger than men (mean age of 27.9 years versus 40.7 years for females and males respectively). The majority of respondents were Fula or Beafada. The distribution of women's ethnicity was similar to men. On average, women had lower education levels than men and $65 \%$ of women had never attended school compared to $18 \%$ of men. Eighty three percent of women and $29 \%$ of men could not read the sample sentence.

\section{Health knowledge}

Table 3 summarises the health knowledge of the interviewees by gender for each of the questions asked. For questions in which only one answer could be given, the number and percentage of interviewees who gave the correct answer is shown. The number and percentage of interviewees giving various numbers of correct answers are provided in the table for questions with more than one correct answer. Knowledge on the prevention and management of diarrhoea was low. Around half of respondents knew that a child with diarrhoea needs to drink more fluids than normal. About the same number recognised a packet of oral rehydration salt (ORS) when it was shown to them. However, only $34 \%$ of women and 
Table 1: Household characteristics

\begin{tabular}{|c|c|c|c|c|c|}
\hline & $\min$ & $\max$ & mean & SD & median \\
\hline \multicolumn{6}{|l|}{ Interviewee responses } \\
\hline Number of people living in household & 3 & 34 & 10.5 & 5.7 & 9 \\
\hline Number of rooms in household & 1 & 12 & 4.6 & 2.1 & 4 \\
\hline Number of people per room & 0.7 & 12 & 2.5 & 1.3 & 2.3 \\
\hline Number of children living in household & 1 & 12 & 2.7 & 1.7 & 2 \\
\hline \multirow[t]{2}{*}{ Number of bed nets in household } & 0 & 13 & 3.6 & 2.2 & 3 \\
\hline & $\begin{array}{l}\text { Number of } \\
\text { households }\end{array}$ & $\%$ & & & \\
\hline \multicolumn{6}{|l|}{ Time since nets were treated } \\
\hline Not needed or within 6 months & 49 & 15.8 & & & \\
\hline Within 1 year & 153 & 49.4 & & & \\
\hline Never/Don't know & 102 & 32.9 & & & \\
\hline No bed nets & 6 & 1.9 & & & \\
\hline Interviewer observations & $\begin{array}{l}\text { Number of } \\
\text { households }\end{array}$ & $\%$ & & & \\
\hline \multicolumn{6}{|l|}{ Hand washing facility where food is prepared } \\
\hline Yes & 253 & 81.6 & & & \\
\hline Soap to wash hands Yes & & 17.1 & & & \\
\hline Latrine type No latrine & 58 & 18.7 & & & \\
\hline Clean* & 185 & 59.7 & & & \\
\hline Covered* & 133 & 42.9 & & & \\
\hline Hand washing facility close to latrine* & 8 & 2.6 & & & \\
\hline
\end{tabular}

*More than one can apply 
Table 2: Demographic characteristics of interviewed women and men

\begin{tabular}{|c|c|c|c|c|}
\hline & \multicolumn{2}{|c|}{ Women } & \multicolumn{2}{|c|}{ Men } \\
\hline & number & $\%$ & number & $\%$ \\
\hline Age (year, mean, SD) & 27.9 & 7.7 & 40.7 & 14.5 \\
\hline \multicolumn{5}{|l|}{ Ethnicity } \\
\hline Balanta & 15 & 4.8 & 15 & 4.8 \\
\hline Beafada & 99 & 31.9 & 97 & 31.3 \\
\hline Fula & 133 & 42.9 & 132 & 42.6 \\
\hline Nalu & 32 & 10.3 & 34 & 11.0 \\
\hline Mandinka & 12 & 3.9 & 12 & 3.9 \\
\hline Susu & 7 & 2.3 & 7 & 2.3 \\
\hline Other & 12 & 3.9 & 13 & 4.2 \\
\hline Never attended school & 202 & 65.2 & 56 & 18.1 \\
\hline \multicolumn{5}{|l|}{ Education level } \\
\hline Primary & 85 & 27.4 & 116 & 37.4 \\
\hline Secondary & 4 & 1.3 & 30 & 9.7 \\
\hline Higher & 0 & 0.0 & 10 & 3.2 \\
\hline Koranic & 19 & 6.1 & 98 & 31.6 \\
\hline Can't read & 257 & 82.9 & 90 & 29.0 \\
\hline
\end{tabular}

$36 \%$ of men knew that a baby aged under six months who has diarrhoea should be given breast milk followed by ORS. Likewise, knowledge on the prevention of malaria was low and $46 \%$ of women and $68 \%$ of men knew that malaria is spread through mosquito bites. Over $56 \%$ of women and $44 \%$ of men could not name any antimalarials that are used to treat malaria. Only $21 \%$ of women and $33 \%$ of men knew that a child taking chloroquine for malaria should be treated for three days, even if they feel better (i.e. they must complete treatment). Very few women (12\%) and men (29\%) stated that they had ever heard the term (pneumonia) and only one woman could give a specific symptom of pneumonia. Nobody knew about the use of antibiotics for treating pneumonia. Whilst the majority of respondents had heard of HIV/ AIDs, very few knew that measles can be prevented by vaccination.

Simple linear regressions (Table 4) showed that women on average scored one point less on health knowledge than men ( $\mathrm{p}<0.001)$, with an overall mean of 5.60 (SD = $0.14)$ and $6.58(\mathrm{SD}=0.14)$ respectively. People with higher levels of education achieved substantially higher scores ( $\mathrm{p}<0.0001)$. Although the number of people living in each room in a household reduced the knowledge score, this reduction was neither substantial nor statistically significant $(\mathrm{p}=0.15)$. The highest knowledge scores 


\section{Table 3: Health knowledge}

\begin{tabular}{|c|c|c|c|c|}
\hline Questionnaire items (number of possible correct answers) & \multicolumn{2}{|c|}{ Women $(\mathbf{N}=\mathbf{3 1 0})$} & \multicolumn{2}{|c|}{ Men $(\mathbf{N}=\mathbf{3 1 0})$} \\
\hline & Number & $\%$ & Number & $\%$ \\
\hline \multicolumn{5}{|l|}{ Number of correct answers given to prevent diarrhoea (4) } \\
\hline 0 & 222 & 71.6 & 194 & 62.6 \\
\hline 1 & 41 & 13.2 & 39 & 12.6 \\
\hline 2 & 45 & 14.5 & 64 & 20.6 \\
\hline 3 & 2 & 0.6 & 13 & 4.2 \\
\hline 4 & 0 & 0.0 & 0 & 0.0 \\
\hline Number said to give more drink to child with diarrhoea & 152 & 49.0 & 161 & 51.9 \\
\hline Number who know ORS & 148 & 47.7 & 144 & 46.5 \\
\hline $\begin{array}{l}\text { Number said to give breast milk followed by ORS if necessary } \\
\text { to a baby under } 6 \text { months with diarrhoea }\end{array}$ & 105 & 33.9 & 112 & 36.1 \\
\hline $\begin{array}{l}\text { Number said to dress lightly and cool child with damp cloth if } \\
\text { child is sick with fever }\end{array}$ & 249 & 80.3 & 242 & 78.1 \\
\hline Number heard about malaria & 277 & 89.4 & 301 & 97.1 \\
\hline $\begin{array}{l}\text { Number said people become infected with malaria from } \\
\text { mosquito bite }\end{array}$ & 141 & 45.5 & 212 & 68.4 \\
\hline
\end{tabular}

Number of correct answers given to avoid malaria (4)

\begin{tabular}{|c|c|c|c|c|c|}
\hline & 0 & 169 & 54.5 & 91 & 29.4 \\
\hline & 1 & 80 & 25.8 & 123 & 39.7 \\
\hline & 2 & 57 & 18.4 & 84 & 27.1 \\
\hline & 3 & 4 & 1.3 & 12 & 3.9 \\
\hline & 4 & 0 & 0.0 & 0 & 0.0 \\
\hline \multicolumn{6}{|l|}{ Number of correct medicines to treat malaria (4) } \\
\hline & 0 & 174 & 56.1 & 137 & 44.2 \\
\hline & 1 & 127 & 41.0 & 156 & 50.3 \\
\hline
\end{tabular}


Table 3: Health knowledge (Continued)

\begin{tabular}{|c|c|c|c|c|}
\hline & 9 & 2.9 & 17 & 5.5 \\
\hline & 0 & 0.0 & 0 & 0.0 \\
\hline & 0 & 0.0 & 0 & 0.0 \\
\hline $\begin{array}{l}\text { Number said to give chloroquine to a child with malaria at least } \\
\text { for } 3 \text { days even if the child gets better }\end{array}$ & 66 & 21.3 & 103 & 33.2 \\
\hline Number heard about pneumonia & 36 & 11.6 & 90 & 29.0 \\
\hline \multicolumn{5}{|l|}{ Number of correct answers given for signs of pneumonia (3) } \\
\hline & 309 & 99.9 & 310 & 100.0 \\
\hline & 1 & 0.003 & 0 & 0.0 \\
\hline Number said that antibiotics are treatment for pneumonia & 0 & 0.0 & 0 & 0.0 \\
\hline Number said vaccine is the correct way to avoid measles & 61 & 19.7 & 65 & 21.0 \\
\hline Number who heard about HIV/AIDS & 280 & 90.3 & 303 & 97.7 \\
\hline
\end{tabular}

were achieved by Nalu (66 respondents) and Balanta (30 respondents), however, the effect of ethnicity was not statistically significant $(\mathrm{p}=0.8)$. With each year increase in age the score is increased by 0.03 ( $p=0.003$ ). Multiple regressions revealed that the apparently lower knowledge score for women was the result of the confounding effect of education level. In the final model, once the effect of gender is controlled for age, education level and ethnicity, women score 0.1 points higher than men and the effect of gender becomes statistically insignificant $(p=0.7)$. The effect of age and education level estimated in this final model did not materially change compared to their effects in the simple regressions. The effect of ethnicity remained statistically insignificant in the multiple regression.

Mothers were also asked questions on exclusive breastfeeding and risk signs during pregnancy. Thirty two percent knew that complementary feeding should start at 6 months and $66 \%$ could not identify any risk signs.

\section{Pregnancy and delivery}

Ninety three percent of women stated that they had received antenatal care (Table 5). The majority of these checkups were conducted in clinics or hospitals (88\%). Most deliveries occurred at home with only around $23 \%$ in a health facility. Health professionals attended $24.4 \%$ of deliveries. In $68 \%$ of deliveries, a razorblade was used to cut the umbilical cord and $79 \%$ of women stated that the equipment used was sterilised. The umbilical cord was reported to be cleaned with alcohol by $17 \%$ of women. Only $25 \%$ of women reported commencing breastfeeding immediately or within one hour of the birth.

\section{Vaccination coverage}

Vaccination coverage for the youngest child of each of the women interviewed is summarised in Table 6. Of the 310 women only 245 had a vaccination card for their youngest child, thus the analysis could only be done for these children. $88 \%$ of children aged one week and over had received their BCG vaccination. Around $90 \%$ of children aged 6 weeks and over had received their OPV1 and DPT1 vaccinations. Vaccination coverage falls as the children get older. $56 \%$ of children who had a vaccination card received vaccinations in regional clinics.

\section{Treatment-seeking behaviour}

Treatment-seeking behaviour of women and men was quite different. Fifty percent of women stated that they would seek help from another parent if a child was sick. In contrast, $60 \%$ of men stated they would seek help from a clinic or a hospital if a child was sick (Table 7). Men and women gave similar reports for the places where medicines for children are normally bought.

Women were also asked whether they can decide by themselves whether or not a seriously ill child should be taken for medical treatment and $71 \%$ stated that they can (data not shown in table). 
Table 4: Linear regressions for health knowledge score (adjusted for clustering in villages)

\begin{tabular}{|c|c|c|c|c|c|c|c|}
\hline \multirow{3}{*}{$\begin{array}{l}\text { variable (unit) } \\
\text { woman vs man }\end{array}$} & \multirow{3}{*}{$\begin{array}{c}\text { number* } \\
\\
-\end{array}$} & \multicolumn{3}{|c|}{ Univariable models } & \multicolumn{3}{|c|}{ Multivariable model } \\
\hline & & \multirow{2}{*}{$\begin{array}{c}\begin{array}{c}\text { change in } \\
\text { score }^{* *}\end{array} \\
-0.97\end{array}$} & \multicolumn{2}{|c|}{$95 \% \mathrm{Cl}$} & \multirow{2}{*}{$\begin{array}{c}\begin{array}{c}\text { change in } \\
\text { score** }\end{array} \\
0.09\end{array}$} & \multicolumn{2}{|c|}{$95 \% \mathrm{Cl}$} \\
\hline & & & -1.29 & -0.66 & & -0.37 & 0.56 \\
\hline age (year) & - & 0.03 & 0.01 & 0.05 & 0.03 & 0.008 & 0.05 \\
\hline \multicolumn{8}{|l|}{$\begin{array}{l}\text { education primary vs } \\
\text { none }\end{array}$} \\
\hline primary vs none & 201 & 1.69 & 1.28 & 2.11 & 1.66 & 1.17 & 2.14 \\
\hline secondary vs none & 34 & 2.83 & 2.09 & 3.57 & 2.90 & 2.07 & 3.73 \\
\hline higher vs none & 10 & 4.78 & 3.87 & 5.69 & 4.91 & 3.89 & 5.93 \\
\hline koranic vs none & 117 & 0.60 & 0.07 & 1.13 & 0.53 & -0.15 & 1.21 \\
\hline $\begin{array}{l}\text { crowdedness (person/ } \\
\text { room) }\end{array}$ & - & -0.16 & -0.38 & 0.06 & - & - & - \\
\hline \multicolumn{8}{|l|}{ ethnicity } \\
\hline beafada vs balanta & 196 & -0.11 & -1.30 & 1.08 & 0.05 & -1.06 & 1.17 \\
\hline fula vs balanta & 265 & -0.24 & -1.39 & 0.92 & -0.24 & -1.31 & 0.82 \\
\hline nalu vs balanta & 66 & 0.20 & -1.08 & 1.48 & -0.13 & -1.28 & 1.01 \\
\hline mandinka vs balanta & 24 & -0.88 & -2.78 & 1.03 & -0.70 & -2.29 & 0.89 \\
\hline susu vs balanta & 14 & -0.69 & -3.18 & 1.81 & -0.79 & -2.38 & 0.81 \\
\hline other vs balanta & 25 & -0.45 & -1.79 & 0.88 & -0.81 & -2.07 & 0.45 \\
\hline
\end{tabular}

* number of the 620 respondents in the given category

** change in the average health knowledge score for a unit increase in the continuous variables or being in a category versus the baseline category for categorical variables.

\section{Discussion}

The study found low levels of appropriate knowledge on child health, some inappropriate practices and generally low vaccination coverage. The study showed that health knowledge scores improve significantly amongst those who have accessed education, in line with other studies $[15,16]$. Regression analysis revealed that differences in health knowledge between women and men become insignificant once age and education are accounted for.
Most of the results presented in this paper are in line with the UNICEF findings on Guinea Bissau in their 2008 report, which tracks the key indicators for monitoring progress to achieve MDG 4 [17]. Any differences might be explained by the fact that part of this study focused on knowledge, whereas the UNICEF report details reported practice. Furthermore, WHO and UNICEF estimate immunisation coverage of $89 \%$ for BCG, $63 \%$ for 3 doses of DPT, $64 \%$ for 3 doses of polio (OPV), and $76 \%$ for measles in 2007 [18]. This is very close to the findings of this 
Table 5: Antenatal care and delivery practices (from the most recent pregnancy)

\begin{tabular}{|c|c|c|}
\hline & Number & $\%$ of women \\
\hline $\begin{array}{l}\text { Number of women received at all } \\
\text { antenatal care }\end{array}$ & 288 & 92.9 \\
\hline \multicolumn{3}{|l|}{ Number of antenatal checkups } \\
\hline 0 & 22 & 7.1 \\
\hline $1-3$ & 74 & 23.9 \\
\hline $4-6$ & 134 & 43.2 \\
\hline $7-9$ & 55 & 17.7 \\
\hline Other & 6 & 1.9 \\
\hline Do not know & 19 & 6.1 \\
\hline
\end{tabular}

Place where checkups happened*

\begin{tabular}{rcc} 
At home by nurse & 2 & 0.6 \\
\hline USB & 33 & 273 \\
\hline regional clinic/NG clinic/hospital & 68.1 \\
\hline Not specified & 6 \\
\hline
\end{tabular}

Place of delivery

\begin{tabular}{|c|c|c|}
\hline Husband home & 163 & 52.6 \\
\hline Parent's home & 53 & 17.1 \\
\hline Someone else's home & 17 & 5.5 \\
\hline USB & 6 & 1.9 \\
\hline Regional clinic & 55 & 17.7 \\
\hline Hospital & 9 & 2.9 \\
\hline Not specified & 7 & 2.3 \\
\hline
\end{tabular}

Attendance at delivery** 
Table 5: Antenatal care and delivery practices (from the most recent pregnancy) (Continued)

\begin{tabular}{|c|c|c|}
\hline Nurse & 28 & 9.0 \\
\hline Midwife & 42 & 13.5 \\
\hline Matrona & 74 & 23.9 \\
\hline Relative & 141 & 45.5 \\
\hline Friend & 16 & 5.2 \\
\hline Not specified & 20 & 6.5 \\
\hline No one & 8 & 2.6 \\
\hline
\end{tabular}

Equipment used to cut umbilical cord

\begin{tabular}{rcr} 
Razorblade & 210 & 67.7 \\
Household knife & 7 & 2.3 \\
\hline Scissors & 51 & 16.5 \\
Other & 2 & 0.6 \\
\hline Do not know & 40 & 12.9
\end{tabular}

Equipment was sterilised

$\begin{array}{ccc}\text { No } & 3 & 1.0 \\ \text { Yes } & 246 & 79.4\end{array}$

Do not know

61

19.7

Equipment sterilisation method

\begin{tabular}{rcc} 
New blade & 215 & 69.4 \\
\hline Alcohol & 12 & 3.9 \\
\hline Heat & 9 & 2.9 \\
\hline Washing with soap & 3 & 1.0 \\
\hline Other & 2 & 0.6 \\
\hline Do not know & 6 & 1.9
\end{tabular}


Table 5: Antenatal care and delivery practices (from the most recent pregnancy) (Continued)

\begin{tabular}{|c|c|c|}
\hline \multicolumn{3}{|l|}{ Umbilical cord dressing *** } \\
\hline Alcohol & 53 & 17.1 \\
\hline Palm Oil & 74 & 23.9 \\
\hline Siti malagos & 3 & 1.0 \\
\hline Bandage & 54 & 17.4 \\
\hline Nothing & 21 & 6.8 \\
\hline Other & 106 & 34.2 \\
\hline Do not know & 42 & 13.5 \\
\hline \multicolumn{3}{|l|}{ Time to put baby on breast after birth } \\
\hline Immediately or within 1 hour & 78 & 25.2 \\
\hline Within 24 hours & 156 & 50.3 \\
\hline Within 3 days & 67 & 21.6 \\
\hline Within 1 week & 7 & 2.3 \\
\hline Within 1 month & 2 & 0.6 \\
\hline
\end{tabular}

study of $88 \%, 66 \%, 62 \%$ and $77 \%$ respectively for the same year.

This study has some limitations. First, the findings of this survey on levels of health knowledge and treatmentseeking and preventative behaviour are only representative of the area selected for the EPICS trial rather than the population of southern Guinea Bissau as a whole. Second, the findings could be biased due to the constraints of conducting research in the difficult conditions of the rainy season. Villages were selected for this survey on the basis of their accessibility, rather than randomly. This resulted in higher numbers of Fula (43\%), lower numbers of Beafada (31\%) and very low numbers of Balanta (5\%) respondents compared to the representation of these groups within the population, based on the enumeration data for the EPICS trial on 7876 women (Beafada (35\%), Fula (17\%) and Balanta (21\%)). This is probably due to the fact that the clustered settlements in which the Beafada and Fula most commonly live are often found in more accessible on-road locations, whereas the scattered settlements in which the Balanta most commonly live are often found further away from the main roads.

Despite its limitations, the method employed in this study has some useful implications for future research. Very few studies of health knowledge and behaviour bring together the range of issues covered in this survey. The majority of studies were conducted on mothers or women of reproductive age on single themes such as the prevention and management or treatment of diarrhoea $[19,20]$, malaria [21,22], and pneumonia [23,24], as well as on knowledge and practice surrounding antenatal care, delivery $[25,26]$ and breastfeeding $[27,28]$. There are a number of studies on health knowledge -- particularly on malaria - which were conducted on both women and men (parents, caregivers, or community members in general) [29-31]. Of the studies mentioned above, many were conducted at the facility level and/or in urban settings and very few studies compared female and male knowledge 
Table 6: Vaccination coverage (from the vaccination card of the youngest child)

\begin{tabular}{|c|c|c|c|c|c|c|c|c|}
\hline \multirow{2}{*}{$\begin{array}{c}\begin{array}{c}\text { age of } \\
\text { youngest }\end{array} \\
\text { child }\end{array}$} & \multirow{2}{*}{\begin{tabular}{|l} 
number \\
with card
\end{tabular}} & \multirow[t]{2}{*}{ Vaccine } & \multicolumn{2}{|c|}{ vaccinated } & \multicolumn{2}{|c|}{ not vaccinated } & \multicolumn{2}{|c|}{ card unreadable } \\
\hline & & & number & $\%$ & number & $\%$ & number & $\%$ \\
\hline$\geq 1$ week & 245 & $\mathrm{BCG}$ & 215 & 87.8 & 27 & 11.0 & 3 & 1.2 \\
\hline$\geq 6$ weeks & 240 & OPV1 & 218 & 90.8 & 18 & 7.5 & 4 & 1.7 \\
\hline $\begin{array}{c}\geq 10 \\
\text { weeks }\end{array}$ & 239 & OPV2 & 175 & 73.2 & 62 & 25.9 & 2 & 0.8 \\
\hline $\begin{array}{c}\geq 14 \\
\text { weeks }\end{array}$ & 234 & OPV3 & 146 & 62.4 & 86 & 36.8 & 2 & 0.8 \\
\hline$\geq 6$ weeks & 240 & DPT1 & 216 & 90.0 & 21 & 8.8 & 3 & 1.2 \\
\hline $\begin{array}{c}\geq 10 \\
\text { weeks }\end{array}$ & 239 & DPT2 & 175 & 73.2 & 63 & 26.4 & 1 & 0.4 \\
\hline $\begin{array}{c}\geq 14 \\
\text { weeks }\end{array}$ & 234 & DPT3 & 154 & 65.8 & 79 & 33.8 & 1 & 0.4 \\
\hline $\begin{array}{c}\geq 9 \\
\text { months }\end{array}$ & 194 & Measles & 149 & 76.8 & 43 & 22.2 & 2 & 1.03 \\
\hline
\end{tabular}

and practice on a range of issues related to child health at the household level in rural settings. An exception is a publication, which examined community effects such as the proportion of literate adults and the presence of a market, on health knowledge in Ghana [15]. As integrated approaches to the reduction of child mortality at the community level become more widespread, it becomes critical to develop tools that can capture a range of knowledge and practice of women and men at the household level in rural settings in order to plan appropriate and effective interventions. The authors believe the survey conducted in this study is a useful contribution to this.

Furthermore, most studies of health knowledge that have been conducted in rural areas of developing countries have reported only descriptive statistics, the numbers and/or percentages of respondents giving correct answers or all the possible correct answers for each individual health knowledge related question, or they derived a simple scoring system which increases by one for each correct answer $[32,33,24]$. In this study, an overall health knowledge score, which is weighted by the inverse of the possible correct answers, has been developed. The authors have used regression analyses, which take into account the clustering of the sample in the villages by using robust standard error estimates, to assess the association between factors and overall health knowledge. As far as the authors are aware, only one group has allowed for hierarchical structure in their analyses [15]. This approach creates new possibilities for measuring changes in health knowledge on multiple issues over time.

Finally, one of the aims of this study was to gather information to inform the development of an appropriate and effective health education programme in southern Guinea Bissau. The study provided critical information for programme planning both in the short and long term. In the short term, targeted programmes have been developed that address key gaps in health knowledge and practice, as outlined by the findings of this survey. These programmes primarily target women as the primary carers of children aged under-five, but they also include men who, as this survey shows, are frequently referred to by their wives when a child is sick. Specifically, the health club methodology [34] has been adapted to address health knowledge and practice in relation to child survival. Health clubs are community associations that hold weekly meetings to discuss health issues in a highly structured participatory framework. This survey provided critical information to develop the content of the health clubs for the intervention (EPICS trial) in southern 
Table 7: Treatment-seeking behaviour

\begin{tabular}{|c|c|c|c|c|}
\hline & \multicolumn{2}{|c|}{ Women ( $N=310)$} & \multicolumn{2}{|c|}{ Men $(N=310)$} \\
\hline & Number & $\%$ & Number & $\%$ \\
\hline \multicolumn{5}{|l|}{$\begin{array}{l}\text { Person from whom } \\
\text { help is sought if child is } \\
\text { ill }\end{array}$} \\
\hline Another Parent & 156 & 50.3 & 14 & 4.5 \\
\hline Relative & 40 & 12.9 & 68 & 21.9 \\
\hline Traditional Healer & 3 & 1.0 & 12 & 3.9 \\
\hline Asc & 7 & 2.3 & 13 & 4.2 \\
\hline Matrona & 2 & 0.7 & 1 & 0.3 \\
\hline Clinic & 84 & 27.1 & 180 & 58.1 \\
\hline Hospital & 1 & 0.3 & 6 & 1.9 \\
\hline Other & 17 & 5.5 & 16 & 5.2 \\
\hline
\end{tabular}

Where is medicine bought normally*

\begin{tabular}{|c|c|c|c|c|}
\hline Local Person & 59 & 19.0 & 56 & 18.1 \\
\hline Relative & 2 & 0.6 & 0 & 0.0 \\
\hline Pharmacy & 111 & 35.8 & 130 & 41.9 \\
\hline USB & 23 & 7.4 & 29 & 9.4 \\
\hline Local Clinic & 182 & 58.7 & 162 & 52.3 \\
\hline Other & 46 & 14.8 & 28 & 9.0 \\
\hline Do Not Know & 0 & 0.0 & 1 & 0.3 \\
\hline
\end{tabular}

Which of the listed

medicine kept at

home*

\begin{tabular}{rcccc}
\hline ORS & 4 & 1.3 & 2 & 0.6 \\
\hline $\begin{array}{r}\text { Chloroquine and/or } \\
\text { Fansidar }\end{array}$ & 15 & 4.8 & 19 & 6.1 \\
\hline
\end{tabular}


Table 7: Treatment-seeking behaviour (Continued)

\begin{tabular}{rcccc}
\hline Paracetamol & 16 & 5.2 & 25 & 9.1 \\
\hline Bactrim & 1 & 0.3 & 3.9 & 1.0 \\
\hline Amoxycilin & 1 & 0.3 & 25 & 8.1 \\
\hline Traditional Medicine & 9 & 2.9 & 40 & 12.9 \\
\hline Other & 23 & 7.4 & 14 & 4.5 \\
\hline Cannot Identify & 9 & 2.9 & 225 & 72.6 \\
\hline
\end{tabular}

${ }^{*}$ more than one answer could be given

Guinea Bissau. In the long term, programmes must be developed that address the chronic lack of access to education in the region, particularly amongst women.

\section{Conclusion}

Prior to planning community-based health education interventions, it is important to conduct properly designed surveys to assess levels of knowledge on child health, treatment-seeking and preventative practices as well as vaccination coverage.

This study found low levels of appropriate health knowledge on diarrhoea, malaria and pneumonia as well as on breastfeeding and risk signs during pregnancy. It also found that the majority of births occurred at home without the presence of a skilled birth attendant and that poor practices existed in relation to the care of the umbilical cord and immediate breastfeeding. The results also showed inappropriate levels of vaccination coverage. Therefore, health education activities that target these areas of knowledge and practice should be an integral part of an intervention package to improve child survival in rural Guinea Bissau.

Although child health education activities often target women only, our study in rural Guinea Bissau showed it could be crucial to involve men in health education activities to improve child survival.

Finally, the derivation of a weighted overall health knowledge score and its use in robust regression analysis is addressing an important methodological issue in assessing health knowledge on multiple topics.

\section{Additional material}

Additional file 1 Health knowledge baseline questionnaire. This file contains the survey questionnaire that was administered in this study.

\section{Competing interests}

The authors declare that they have no competing interests.

\section{Authors' contributions}

RK contributed to the conception and design of the study, the acquisition of data, the interpretation of the data, and the drafting of the manuscript. VM contributed to the conception and design of the study, the analysis and interpretation of the data, and the drafting of the manuscript. PB contributed to the conception and design of the study and the revision of the manuscript. All authors read and approved the final manuscript.

\section{Acknowledgements}

The authors would like to thank the following for their contributions: Kalie Sassoon, Albino dos Santos and the field team for acquisition of data; Mark Fisher for database design; Ila Fazzio, Jose Carlos de Sa and Polly Walker for advice on study design; Adil Shah for logistical support; and Chitra Jayanty for advice and support.

All individuals mentioned above were funded by Effective Intervention.

This study, the authors, and the preparation of the manuscript were funded by Effective Intervention.

\section{Author Details}

1 Effective Intervention, Centre for Economic Performance, London School of Economics, London, UK, 2 Medical Statistics Unit, Department of Epidemiology and Population Health, London School of Hygiene and Tropical Medicine, London, UK and ${ }^{3}$ The Nuffield Centre for International Health and

Development, Leeds Institute of Health Sciences, University of Leeds, Leeds, UK

Received: 9 December 2009 Accepted: 8 June 2010

Published: 8 June 2010

\section{References}

1. Black RE, Morris SS, Bryce J: Where and why are 10 million children dying every year? Lancet 2003, 361:2226-34

2. Jones G, Steketee RW, Black RE, Bhutta ZA, Morris SS, The Bellagio Child Survival Study Group: How many child deaths can we prevent this year? Lancet 2003, 362:65-71.

3. Bryce J, Arifeen S, Pariyo G, Lanata CF, Gwatkin D, Habicht JP, The MultiCountry Evaluation of IMCI Study Group: Reducing child mortality: can public health deliver? Lancet 2003, 362:159-64.

4. Victoria CG, Wagstaff A, Schellenberg JA, Gwatkin D, Claeson M, Habicht JP: Applying an equity lens to child health and mortality: more of the same is not enough. Lancet 2003, 362:233-41.

5. The Bellagio Study Group on Child Survival: Knowledge into action for child survival. Lancet 2003, 362:323-27.

6. UNICEF: UNICEF/WHO Meeting on Child Survival Survey-based Indicators, New-York 2004. 
7. Bhutta ZA, Darmstadt GL, Hasan BS, Haws RA: Community-based interventions for improving perinatal and neonatal health outcomes in developing countries: a review of the evidence. Pediatrics 2005, 115:519-617.

8. Rosato M, Laverack G, Grabman LH, Tripathy P, Nair N, Mwansambo C, Azad K, Morrison J, Bhutta Z, Perry H, Rifkin S, Costello A: Community participation: lessons for maternal, newborn, and child health. Lancet 2008, 372:962-71.

9. Manandhar DS, Osrin D, Shrestha BP, Mesko M, Morrison J, Tumbahangphe K, Tamang S, Thapa S, Shrestha D, Thapa B, Shrestha JR, Wade A, Borghi J, Standing H, Manandhar M, Cosetello A, MIRA Makwanpur trial team: Effect of a participatory intervention with women's groups on birth outcomes in Nepal: cluster-randomised controlled trial. Lancet 2004, 364:970-979.

10. O'Rourke K, Howard-Grabman L, Seoane G: Impact of community organization of women on perinatal outcomes in rural Bolivia. Pan Am J Public Health 1998, 3(1):9-14.

11. Howard-Grabman L, Seoane G, Davenport C, MotherCare, Save the Children: The Warmi Project: a participatory approach to improve maternal and neonatal health: An implementer's manual Westport: John Snow International, Mothercare Project, Save the Children; 2002

12. Bang AT, Bang RA, Baitule SB, Reddy MH, Deshmukh MD: Effect of homebased neonatal care and management of sepsis on neonatal mortality: field trial in rural India. Lancet 1999, 354:1955-61.

13. UNICEF: The State of the World's Children 2009: Tracking maternal and newborn health. New York 2009.

14. Mann V, Fazzio I, King R, Walker P, dos Santos A, de Sa JC, Jayanty C, Frost C, Elbourne D, Boone P: The EPICS Trial: Enabling Parents to Increase Child Survival through the introduction of community-based health interventions in rural Guinea Bissau. BMC Public Health 2009, 9:279.

15. Andrzejewski CS, Reed HE, White MJ: Does where you live influence what you know? Community effects on health knowledge in Ghana. Health and Place 2009, 15:228-238.

16. Glewwe $P$ : Why does mother's schooling raise child health in developing countries: evidence from Morocco. The Journal of Human Resources 1999, 34(1):124-136.

17. UNICEF: Tracking Progress in Maternal, Newborn \& Child Survival. The 2008 Report. New York 2008

18. WHO/UNICEF Review of National Immunization Coverage 1980-2008. Guinea Bissau [http://www.who.int/immunization monitoring/data/ gnb.pdf]. (accessed 26 November 2009)

19. Rasania SK, Pathi D, Matta S, Singh S: Knowledge and attitude of mothers about oral rehydration solution in few urban slums of Delhi. Health and Population Perspectives and Issues 2005, 28(2):100-107.

20. Taha AZ: Assessment of mother's knowledge and practice in use of oral rehydration solution for diarrhoea in rural Bangladesh. Saudi Medical Journal 2002, 23(8):904-908.

21. Rakhshani F, Moghadam ARA, Alemi R, Moradi A: Knowledge, perceptions and prevention of malaria among women in Sistan va Baluchestan, Islamic Republic of Iran. Eastern Mediterranean Health Journal 2003, 9(3):248-256.

22. Seck I, Fall IS, Faye A, Ba O, Tal-Dia A: Malaria knowledge, attitudes and practices among women living in the rural area of Poponguine, Senegal. Revue Medecine Tropicale 2008, 68(6):629-633.

23. Galvez CA, Modeste N, Lee JW, Betancourt H, Wilkins RL: Peruvian mothers' knowledge and recognition of pneumonia in children under 5 years of age. Revista Panamericana de Salud Publica/Pan American Journal of Public Health 2002, 11(2):99-108.

24. Uwaezuoke SN, Emodi IJ, Ibe BC: Maternal perception of pneumonia in children: a health facility survey in Enugu, eastern Nigeria. Annals of Tropical Paediatrics 2002, 22(3):281-285.

25. Abdulsalam A: Syrian women's preferences for birth attendant and birth place. Birth 2005, 32(1):20-26.

26. Mayhew M, Hansen PM, Peters DH, Edwards A, Singh LP, Dwivedi V, Mashkoor A, Burdham G: Determinants of skilled birth attendant utilization in Afghanistan: a cross-sectional study. American Journal of Public Health 2008, 98(10):1849-1856

27. Chandrashekhar TS, Joshi HS, Binu V, Shankar PR, Rana MS, Ramachandran $\mathrm{U}$ : Breast-feeding initiation and determinants of exclusive breastfeeding - a questionnaire survey in an urban population of western Nepal. Public Health Nutrition 2007, 10(2):192-197.
28. Chatman LM, Salihu HM, Roofe ME, Wheatle P, Henry D, Jolly PE: Influence of knowledge and attitudes on exclusive breastfeeding practice among rural Jamaican mothers. Birth 2004, 31(4):265-271.

29. Al-Taiar A, Chandler S, Al Eryani S, Whitty CJ: Knowledge and practices for preventing severe malaria in Yemen: the importance of gender in planning policy. Health Policy and Planning 2009, 24(6):428-37.

30. Hlongwana KW, Mabaso ML, Kunene S, Govender D, Maharaj R: Community knowledge, attitudes and practices (KAP) on malaria in Swaziland: a country earmarked for malaria elimination. Malaria Journal 2009, 8:29.

31. Oguonu T, Okafor HU, Obu HA: Caregivers' knowledge, attitude and practice on childhood malaria and treatment in urban and rura communities in Enugu, south-east Nigeria. Public Health 2005 119(5):409-414

32. Hadi A: Promoting health knowledge through micro-credit programmes; experience of BRAC in Bangladesh. Health Promotion International 2001, 16(3):219-227.

33. Senarath U, Fernando DN, Vimpani G, Rodrigo I: Factors associated with maternal knowledge of newborn care among hospital-delivered mothers in Sri Lanka. Transactions of the Royal Society of Tropical Medicine and Hygiene 2007, 101(8):823-830.

34. Waterkeyn J, Cairncross S: Creating demand for sanitation and hygiene through Community Health Clubs: A cost-effective intervention in two districts in Zimbabwe. Social Science \& Medicine 2005, 61:1970.

\section{Pre-publication history}

The pre-publication history for this paper can be accessed here: http://www.biomedcentral.com/1471-2458/10/319/prepub

doi: 10.1186/1471-2458-10-319

Cite this article as: King et al., Knowledge and reported practices of men and women on maternal and child health in rural Guinea Bissau: a cross sectional survey BMC Public Health 2010, 10:319

\section{Submit your next manuscript to BioMed Central and take full advantage of:}

- Convenient online submission

- Thorough peer review

- No space constraints or color figure charges

- Immediate publication on acceptance

- Inclusion in PubMed, CAS, Scopus and Google Scholar

- Research which is freely available for redistribution
C Biomed Central 